\title{
Eurycoma longifolia Root Aqueous Extract Augments the Testosterone Level and Spermatogenesis in Adult Male Rats
}

\author{
Hamoud H. Al-Faqeh ${ }^{a}$, Mohammed Imad AMM ${ }^{b}$

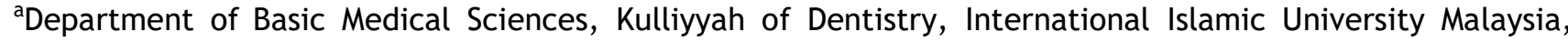 \\ 25200 Kuantan, Pahang, Malaysia \\ bepartment of Basic Medical Sciences, Kulliyyah of Medicine, International Islamic University Malaysia, \\ 25200 Kuantan, Pahang, Malaysia
}

\section{ABSTRACT}

Introduction The Eurycoma longifolia (EL) root aqueous extract has long been used as an enhancer of male sexual performance. However, data from previous studies in both human males and experimental male animals on the testosterone level in those given the EL extract orally were at best insufficiently conclusive. Materials and Method Sixty-four healthy adult male Sprague Dawley rats were acclimatized, and randomized into six test groups and one control group. All rats where given either the aqueous EL extract or distilled water via metal gavage needle. The first three test groups received the low (50mg/kg bw), medium (100mg/ $\mathrm{kg} \mathrm{bw})$ and high $(200 \mathrm{mg} / \mathrm{kg} \mathrm{bw})$ doses respectively of the EL daily for 15 days only. The second three test groups continued receiving the same daily treatment doses for 30 days. The controls were given distilled water only. At the end of each of the study period, blood samples were collected via cardiac puncture and the rats were euthanized. The testicles were obtained, weighed, and processed for histological examination. Results The sera testosterone levels were higher in animals which received the medium and high doses for both treatment duration. Rats which received medium and high oral doses of EL showed an increase of spermatogenesis and mature spermatozoa. Conclusion The optimal enhancing effect on sera testosterone levels and testicular spermatogenesis of EL treatment in adult male rats was observed with the medium dose of $100 \mathrm{mg} / \mathrm{kg}$ bw given once daily for both 15 and 30 days.

KEYWORDS: Eurycoma longifolia; Testosterone; Rat; Testes; Histology

\section{INTRODUCTION}

Eurycoma longifolia (EL) belongs to the plant family Simaroubaceae. It contains quassinoids such as eurycomalacton, eurycomanon and eurycomanol which have been reported to have aphrodisiac properties and to increase testosterone levels in men. ${ }^{1}$ Testosterone is an important hormone that regulates male sexual performance and disputably the female sexual libido too. ${ }^{2}$ On the other hand low levels of testosterone will reduce male and probably female sexual desire. ${ }^{3}$ EL has been reported as a

Corresponding Author:

Dr. Hamoud H. Al-Faqeh

Department of Basic Medical Sciences,

Kulliyyah of Dentistry,

International Islamic University Malaysia,

25200 Kuantan, Pahang, Malaysia

Tel : +60199993948 .

Email: fanousi08@gmail.com traditional remedy for vitality, energy and aphrodisiac activities. ${ }^{4}$ The EL root aqueous extract is used traditionally as remedy for enhancing testosterone level in man due to its bioactive compounds. ${ }^{4}$ Studies on the effects of EL on erectile dysfunction, decreased libido, low testosterone level and hypogonadism have shown promising results in terms of improving male sexual health. ${ }^{5}$ A study was performed in the male rat model concluded that EL reversed the effects of oestrogen and improved spermatogenesis and sperm count. ${ }^{6}$ On the other hand clinical studies have shown that the sperm quality of idiopathic infertile males and the testosterone level of late-onset hypogonadism were improved when treated with the EL extract. ${ }^{7}$ Since there were insufficient studies supporting the potential role of EL root aqueous extract in boosting blood testosterone level, the present study aimed to investigate the effect of EL root aqueous extract on spermatogenesis and testosterone level in the sera of 
adult male rats. It has been previously reported that rats which received $200 \mathrm{mg}$ daily of EL aqueous extract for four weeks showed improvements in testosterone level in all the subjects treated with subsequent enhancement in sexual activities. ${ }^{8}$

\section{MATERIALS AND METHODS}

A total of sixty-four healthy adult male Sprague Dawley rats weighing 300-350g were purchased from the animal breeding laboratory in University Putra Malaysia (UPM), Malaysia. Before the start of the study, the rats were kept in our facility for two weeks to acclimatize before starting the experiment. All rats had free access to food and drink. This study was conducted after obtaining approval from the Institutional Animal Care Committee [IIUM/IACUC Approval/2016/(11)(78)].

Rats were randomized into six treated groups and one control group. There were eight rats in each group. All rats in the treated groups were given the oral extract solution, and rats in control group given distilled water (DW) only. The extract and DW were administered via metal gavage needle 18G. The EL extract was dissolved in DW. Three of the six test groups received EL extract daily for 15 days at three different doses: low dose $(50 \mathrm{mg} / \mathrm{kg}$ bw), medium dose $(100 \mathrm{mg} / \mathrm{kg} \mathrm{bw})$ and high dose $(200 \mathrm{mg} / \mathrm{kg} \mathrm{bw})$ respectively. The other three test groups received the same daily doses but for 30 days. The oral LD50 of the aqueous extract of EL is more than $3000 \mathrm{mg} /$ kg. ${ }^{9}$ Four rats each were placed in transparent plastic cages kept at $25 \pm 2^{\circ} \mathrm{C}$ under natural day/ night cycle and were fed with commercial rat chow and drinking water.

EL roots aqueous extract powder was supplied by $L$ Jack (M) Sdn. Bhd. (Malaysia) L Jack 100 (Batch no TAE030317). ELISA KIT for testosterone level measurement was purchased from CUSABIO-USA. By the end of the study period of 15 days and 30 days respectively, approximately 4 to $5 \mathrm{ml}$ of blood sample was obtained from each rat via cardiac puncture using $23 \mathrm{G}$ needle into vacutainer tubes. They were stored at $4^{\circ} \mathrm{C}$ for 8 hours to clot then centrifuged at $3000 \mathrm{rpm}$ for 7 minutes. The sera were then collected and stored at $-80^{\circ} \mathrm{C}$ until the time of testosterone level measurement. The testosterone levels in the sera were measured according to the kit protocol, using the fourparameter Logistic Curve (log-log). After the blood sample was obtained, rats were euthanized and both testicles from each rat were collected, washed with normal saline, wiped and weighed, then fixed in $10 \%$ phosphate-buffered formaldehyde until conventional processing and staining of $5 \mu \mathrm{m}$ sections by Haematoxylin and Eosin (H\&E) for histological examination. The relative testicular weight was calculated as follows [gross testicular (g) / gross rat body weight] $\times 100$.

\section{Statistical Analysis.}

The results are expressed as mean \pm standard error of mean (SEM). Data analysis was performed using Statistical Package Software (SPSS Statistics v20). One-way analysis of variance (ANOVA) followed by post hoc Tukey test was used to test the sera testosterone level data for significance. Histological samples underwent qualitative analysis.

\section{RESULTS}

\section{Clinical observations}

All experimental rats appeared active and healthy during the acclimatization period and during the experiment. There were no evidence of infection or mortality due to the EL treatment during the experiment. All rats gained weight normally during the entire duration of the study. All test rats tolerated well, the various oral doses of EL from low to high doses.

\section{Gross and relative testicular weight}

Although the testicular gross and relative weights showed an increasing trend in the treated groups which corresponds with the increasing oral dose of EL aqueous extract for 30 days however these differences were not statistically significant $(p>0.05)$, as shown in Figures $1 \mathrm{a} \& 1 \mathrm{~b}$.

\section{Histological observation of the testicular tissue}

The histological appearances of the testicular tissues from treated groups and control are shown in Figures 2 \& 3 . However, the rats treated with low dose ( $50 \mathrm{mg} / \mathrm{kg}$ bw) either for 15 or 30 days did not show any apparent increase of spermatocytes and mature spermatozoa at the end of the experiment compared to the control group (Figures $2 a, 2 b \& 3 a, 3 b$ ). Interestingly rats that received medium dose (100 


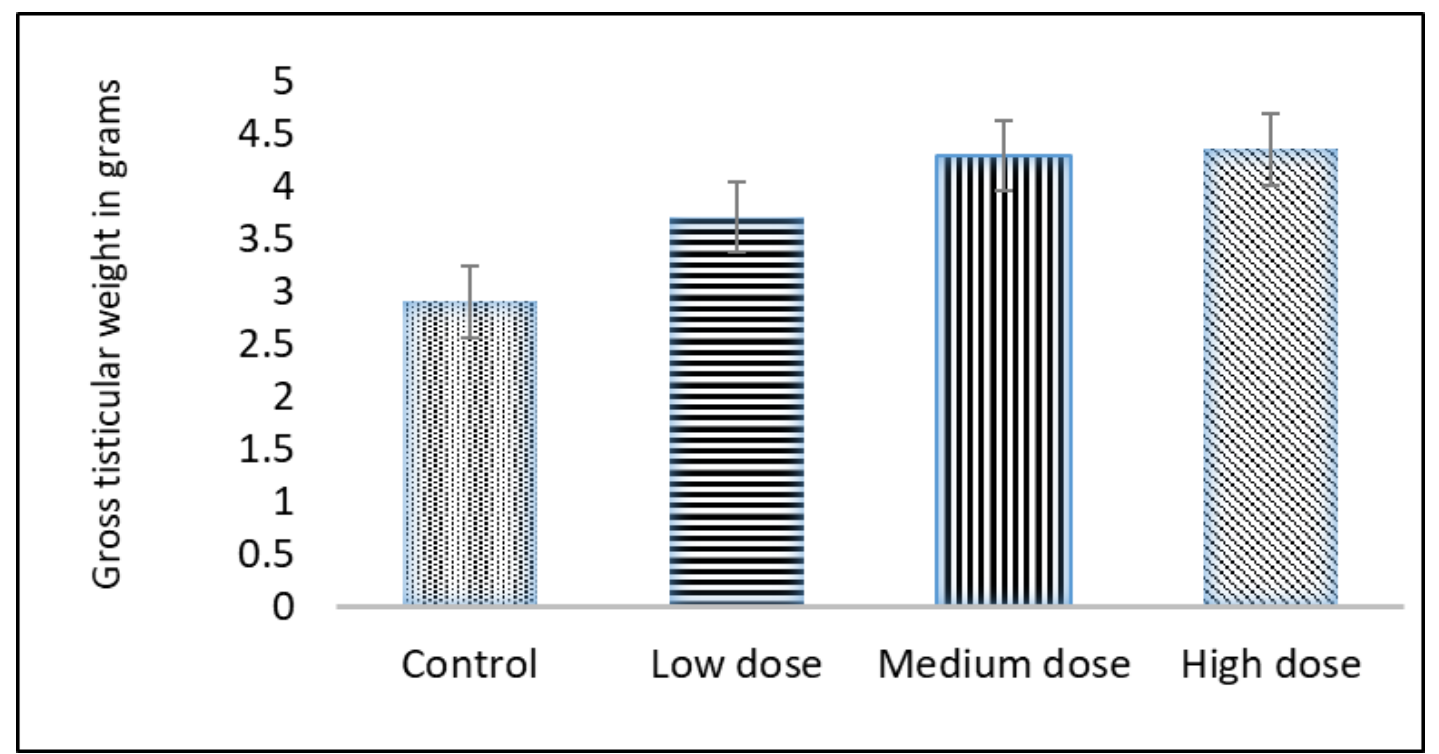

Figure 1a The mean gross testicular weight (grams) in treated male rats and control groups $(p>0.05)$ over 30 days duration.

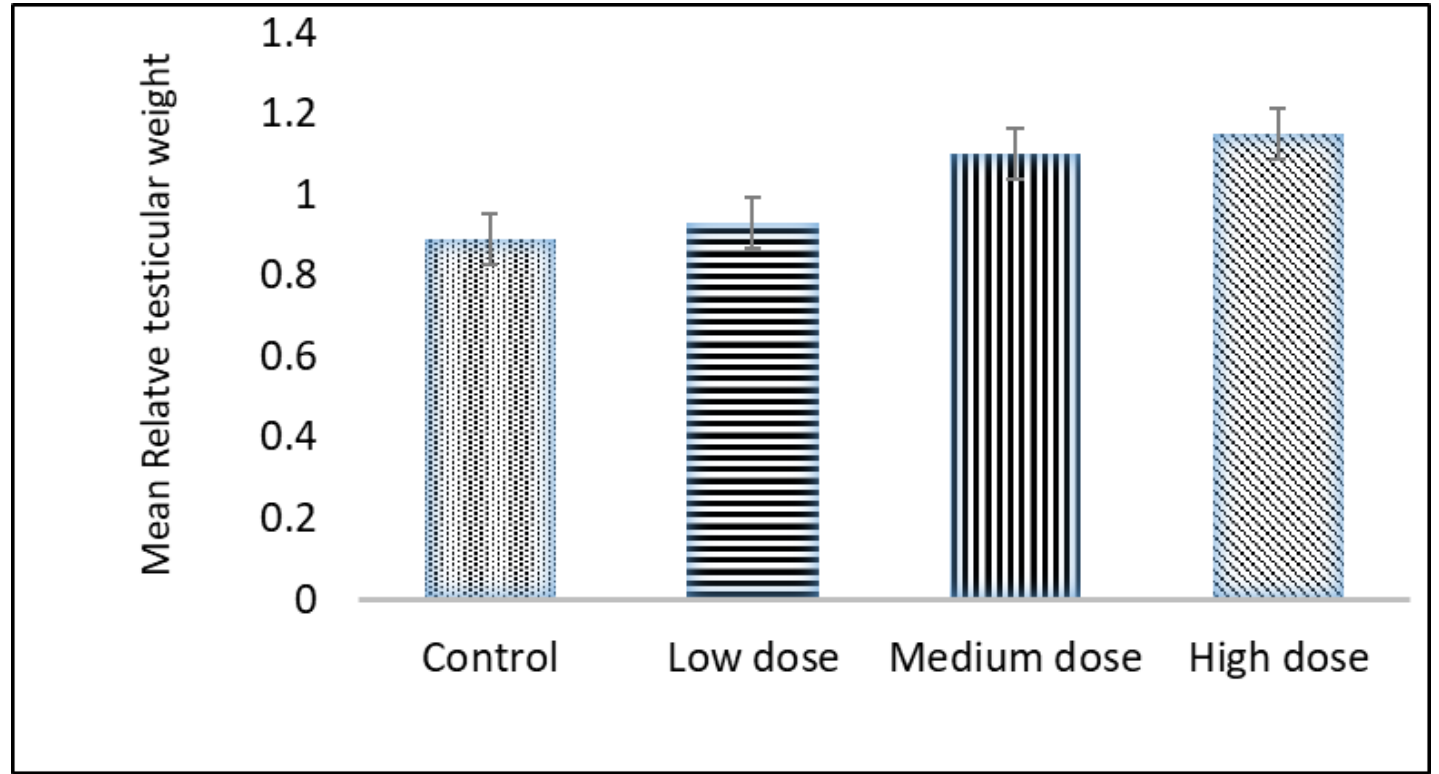

Figure $1 \mathrm{~b}$ The mean gross and relative testicular weight in treated male rats and control groups over 30 days duration.

$\mathrm{mg} / \mathrm{kg}$ bw) and high dose ( $200 \mathrm{mg} / \mathrm{kg}$ bw) regardless of duration of treatment showed increase in spermatogenesis, mature spermatozoa, Sertoli and Leydig cells (Figures $2 c \& 2 d$ and Figures $3 c-3 d$ ). On the other hand, seminiferous tubules of the testes of rats which received medium and high doses of EL appeared more packed with spermatocytes and mature spermatozoa as compared to that of the low dose and control groups as shown in Figures 2 \& 3 .

\section{Testosterone Level Profile}

The mean testosterone levels in sera from control rats and those treated with high, medium and low doses of EL aqueous extracts orally for 15 days and
30 days are presented in Figure 4 . Although the data showed that the testosterone levels were higher among animals that received the medium and high dose for 15 days $(0.802 \mathrm{ng} / \mathrm{mL}$ and $0.705 \mathrm{ng} / \mathrm{mL}$ respectively) versus those treated for 30 days $(0.702$ $\mathrm{ng} / \mathrm{mL}$ and $0.575 \mathrm{ng} / \mathrm{mL}$ respectively) the differences were not statistically significant. In the low dose treated group levels were lower when compared to the medium and high dose, but higher than the controls, being $0.35 \mathrm{ng} / \mathrm{mL}$ and $0.4 \mathrm{ng} / \mathrm{mL}$ respectively for the 15 days and 30days. However, all EL treated groups had testosterone levels that were significantly higher than the control group $(p<0.05$, as presented in the Figures 4. 


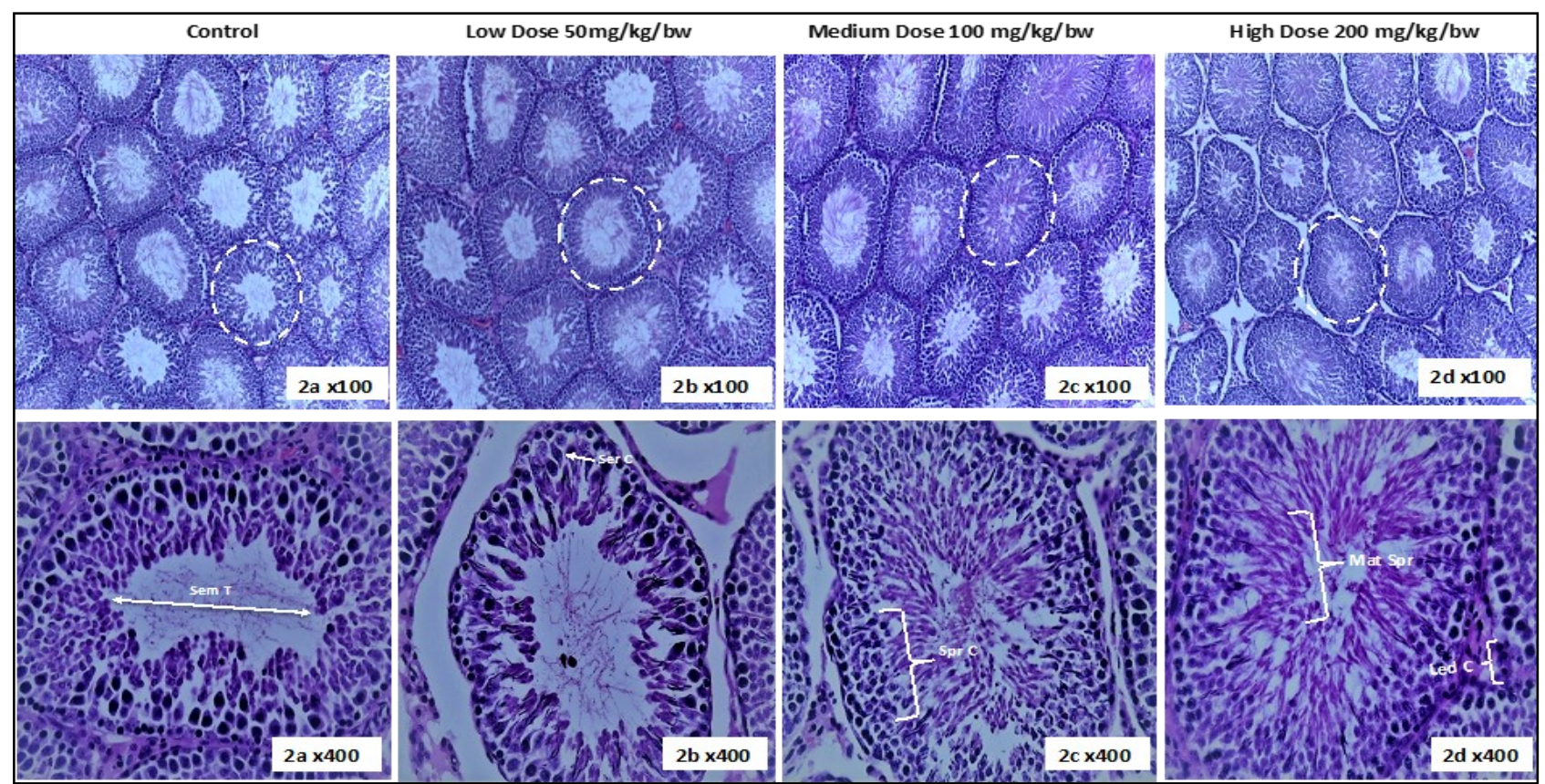

Figure 2 Cross section of the adult male rat testicular tissue of control group (2a) and test groups (2b-d) treated with Eurycoma longifolia (EL) root aqueous extract for 15 days. Control group (2a) received distilled water only. Test groups received low dose ( $50 \mathrm{mg} / \mathrm{kg} \mathrm{bw})(2 \mathrm{~b})$, medium dose $(100 \mathrm{mg} / \mathrm{kg}$ bw) (2c) and high dose $(200 \mathrm{mg} / \mathrm{kg} \mathrm{bw})(2 \mathrm{~d})$ respectively. Rats which received low dose $(50 \mathrm{mg} / \mathrm{kg}$ bw) (2b) exhibited normal testicular tissue texture when compared to control (2a). Rats which received medium dose $(100 \mathrm{mg} / \mathrm{kg} \mathrm{bw})(2 \mathrm{c})$ \& high dose $(200 \mathrm{mg} / \mathrm{kg} \mathrm{bw})(2 \mathrm{~d})$ exhibited dense spermatocytes when compared to low dose $(2 b)$ and control $(2 a)$. There were no signs of testicular tissue degeneration, haemorrhage and fatty changes; and testicular architecture remained intact of the experimental animals following once daily, oral EL treatment. Tissues were stained with Haematoxylin and Eosin (H\&E). Original magnification $\times 100 \& \times 400$. SemT=seminiferous tubule, Spr C= Spermatocytes, Led C= Leydig Cells, Ser C= Sertoli cells \& Mat Spr= Mature Spermatozoa.

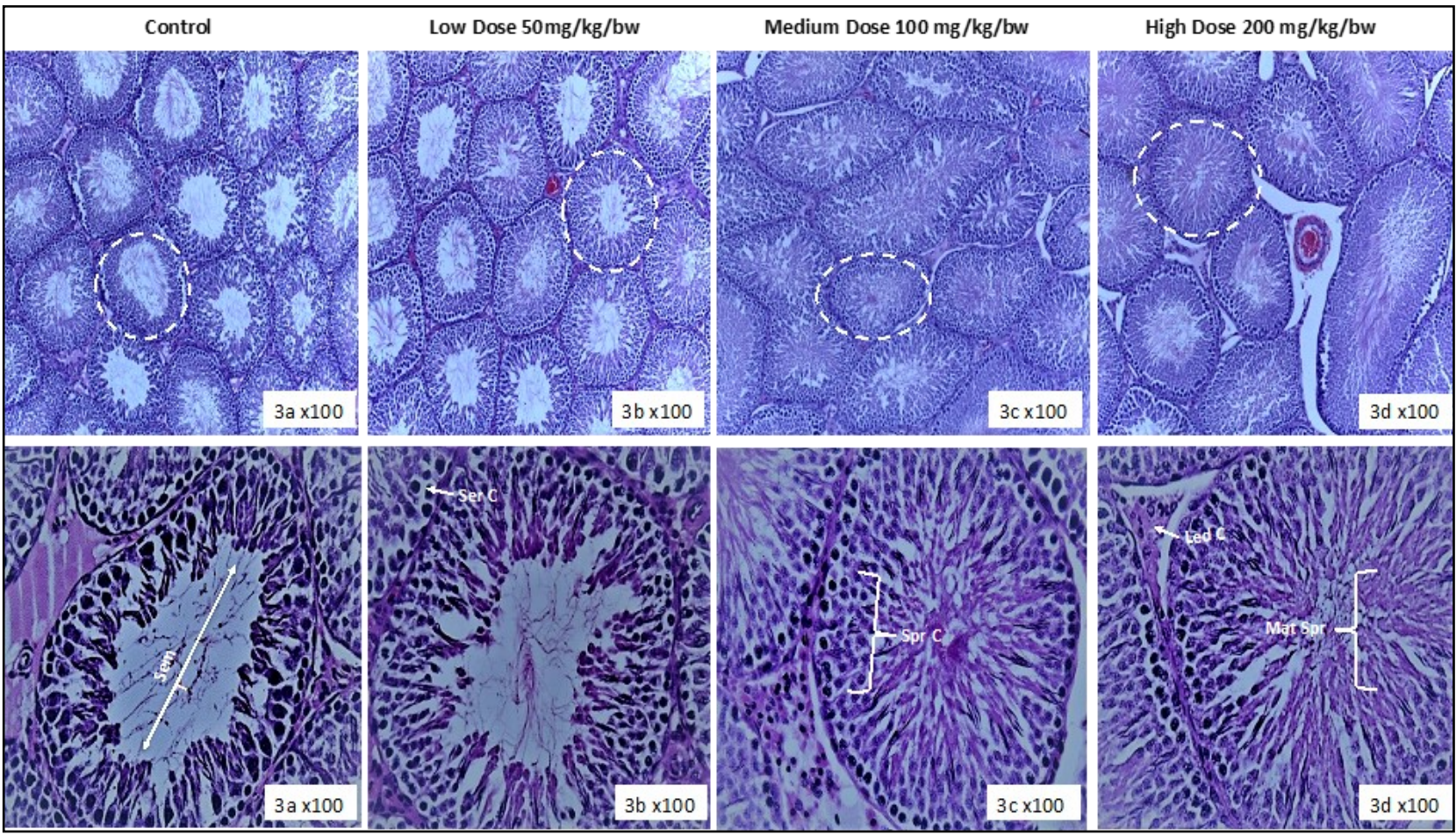

Figure 3 Cross section of the adult male rat testicular tissue of control group ( $3 a$ ) and test groups (3b-d) treated with Eurycoma longifolia (EL) root aqueous extract for 30 days. Control group (3a) received distilled water only. Test groups received low dose (50 mg/kg bw) (3b), medium dose $(100 \mathrm{mg} / \mathrm{kg} \mathrm{bw})(3 \mathrm{c})$ and high dose $(200 \mathrm{mg} / \mathrm{kg} \mathrm{bw})(3 \mathrm{~d})$ respectively. Rats which received low dose $(50 \mathrm{mg} / \mathrm{kg}$ bw) (3b) exhibited normal testicular tissue texture when compared to control (3a). Rats which received medium dose $(100 \mathrm{mg} / \mathrm{kg} \mathrm{bw}$ ) (3c) \& high dose (200 mg/kg bw) (3d) exhibited dense spermatocytes when compared to low dose (3b) and control (3a). There were no signs of testicular tissue degeneration, haemorrhage and fatty changes; and testicular architecture remained intact of the experimental animals following once daily, oral EL treatment. Tissues were stained with Haematoxylin and Eosin (H\&E). Original magnification $\times 100 \& \times 400$. SemT=seminiferous tubule, Spr C= Spermatocytes, Led C= Leydig Cells, Ser C= Sertoli cells \& Mat Spr= Mature Spermatozoa. 


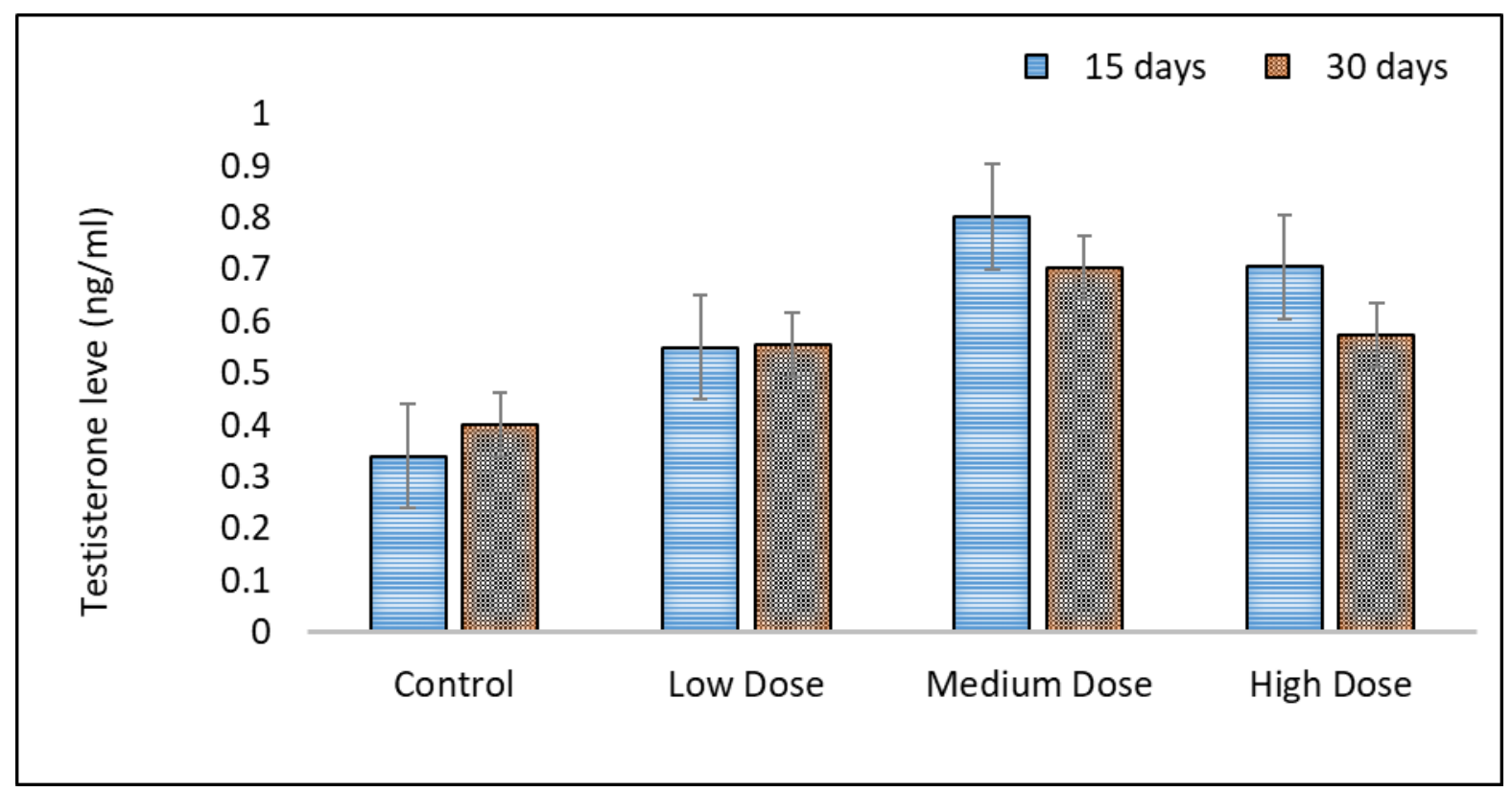

Figure 4 The mean sera testosterone levels in Eurycoma longifolia (EL) root aqueous extract treated adult male rats over 15 days and 30 days.

\section{DISCUSSION}

Eurycoma longifolia (EL) has been well recognized as a booster of male sexual health. Over the past few decades, numerous in vivo animal studies and human clinical trials have been conducted across the globe to explore the promising role of EL in managing various male sexual disorders, which include erectile dysfunction, male infertility, low libido, and down-regulated testosterone levels. ${ }^{5}$

In this study we strived to investigate both the dose response and duration of treatment effects on the sera testosterone levels in adult male rats treated with oral EL root aqueous extract in three different doses of 50,100 and $200 \mathrm{mg} / \mathrm{kg}$ bw for 15 days and 30 days. This finding conquers with previous study conducted on men with the average age 51 years old with low testosterone levels who were treated with one month daily supplementation with EL extract $(200 \mathrm{mg} /$ day) which resulted in a significant improvement in sera testosterone levels and qualityof-life parameters.

The quassinoids in EL extract are responsible for the improved spermatogenesis and fertility. Eurycoma longifolia extract, increased testosterone production in the isolated rat testicular Leydig cell-rich interstitial cells. ${ }^{10}$ A clear trend of rising testosterone level in response to higher doses and duration of EL treatment was noted in this study. However, the differences were most noticeable when comparing low dose with both the medium and high doses. Comparison between the medium and high doses was not statistically significant, however higher testosterone level was noted at the medium rather than to the high dose EL treatment. This may be explained by a saturation effect above which the testosterone response does not go any higher and may even start to drop.

The histological examination in this study showed increase in spermatozoa and spermatogenesis. This result was supported by the previous study conducted on male rats which reported that oral supplement of EL over 30 days improved spermatogenesis in the testicular tissue, thus concluding that EL may potentially be beneficial for the management of male infertility. ${ }^{5}$ Another study conducted on adult male rats had shown that EL extract acts as a potential agent for reversing the effects of oestrogen by increasing spermatogenesis and sperm counts in rats after 14 consecutive days of treatment. ${ }^{7}$

The subtle differences in testosterone levels reported in this study between the medium and high doses treated animal groups may be due to the known variations in testosterone levels that may naturally occur even within the same day due to sexual arousal. We tried to limit the effect of this confounding factor by sacrificing the animals and obtaining the blood samples at nearly similar time of the day for all groups. From the histological examination of the testicles we observed an increase of mature 
spermatocytes and spermatozoa in test animal groups treated with the medium and high doses of EL extract for 15 days or 30 days, as compared with the control and low dose groups. In this study the increase of testosterone levels in the sera of rats treated with medium and high doses of EL were supported and reflected by the testicular increase of spermatozoa and matured spermatocytes. These findings are in concordance with results from previous work conducted on adult rats that showed treatment with EL extract increased testosterone production in the isolated rat testicular Leydig cellrich interstitial cells. ${ }^{7}$ EL modulated on testosterone and oestrogen production in the male rat testicular Leydig cell-rich interstitial cells and, the resultant increase of testosterone production may therefore improve spermatogenesis and male fertility. ${ }^{10}$ Another study was conducted on male rats also showed that the sperm count and spermatogenic cell count were increased in EL treated group as compared with control group. ${ }^{11} \mathrm{EL}$ is thought to be potentially capable of suppressing the harmful effects of oestradiol on spermatogenesis and sperm counts in healthy male rats when given for 14 consecutive days. ${ }^{11}$ A study was conducted on rats showed the oral LD50 of the EL aqueous extract is more than $3000 \mathrm{mg} / \mathrm{kg}$. ${ }^{9}$ Therefore, our given doses of $50 \mathrm{mg} / \mathrm{kg}, 100 \mathrm{mg} / \mathrm{kg}$ and $200 \mathrm{mg} / \mathrm{kg}$ respectively are regarded as safe.

\section{CONCLUSION}

The oral administration of Eurycoma longifolia root aqueous extract has an enhancing effect on both the blood testosterone levels and testicular spermatogenesis with medium and high doses of 100 and $200 \mathrm{mg} / \mathrm{kg}$ bw respectively for treatment periods of both 15 days and 30 days with more pronounced effect after 30 days. However, differences between the tested effects at these two doses were not statistically significant. Thus, the observed optimal enhancing effects of EL treatment on both blood testosterone levels and testicular spermatogenesis is best achieved with the medium dose given either for 15 or 30 days.

\section{CONFLICT OF INTEREST}

This study was funded by $L$ Jack (M) Sdn. Bhd. which also supplied the Eurycoma longifolia root aqueous extract.

\section{ACKNOWLEDGEMENTS}

The study conducted after permission was obtained from Research Management Centre (RMC), Project ID: SP16-019-0232. International Islamic University Malaysia (IIUM). The authors are also thankful to the Kulliyyah of Medicine, IIUM for providing all research facilities to accomplish this research. Special thanks should be given to Mr. Md Isa Bin Mehat for his help as research assistant and Mrs Nur Sazwi Nordin for her help in ELISA assay.

\section{REFERENCES}

1. Hamzah S, Yusof A. The ergogenic effects of Eurycoma longifolia Jack: A pilot study. $\mathrm{Br} \mathrm{J}$ Sports Med 2003;37:465 466.

2. Cappellettia M, Wallena K. Increasing women's sexual desire: The comparative effectiveness of estrogens and androgens. Horm Behav. 2016;78:178-193.

3. Ang HH, Cheang HS, Yusof APM. Effects of Eurycoma longifolia Jack (Tongkat Ali) on the initiation of sexual performance of inexperienced castrated male rats. J Exp Anim 2000;49:35-38.

4. Bhat R, Karim AA. Eurycoma Longifola Jack: a review on its ethnobotany and pharmacological importance," Fitoterapia 2010;81:669-679.

5. Thu HE, Mohamed IN, Hussain Z, Jayusman PA, Shuid AN. Eurycoma longifolia as a potential adaptogen of male sexual health: a systematic review on clinical studies. Chinese Journal of Natural Medicines 2017;15:71- 80.

6. Wahab NA, Mokhtar NM, Halim WNHA, et al. The effect of Eurycoma longifolia Jack on spermatogenesis in oestrogen- treated rats. Journal of Clinics 2010;65:93-98.

7. Tambi MIBM, Imran MK, Henkel RR. Standardised water-soluble extract of Eurycoma longfolia, Tongkat Ali, a stestosterone booster for managing men with late-onset hypogonadism. Andrologia. 2012; Suppl 1:226-30.

8. Sheng Li Xue Bao. Periodic changes in sera testosterone levels after ejaculation in men. J.Acta Physiologica Sin 2012;54:535-538.

9. Hamoud Hussein Al-Faqeh, Bala Yauri Muhammad, Emad Mohammed Nafie and Anuar Khorshid. The effect of Eurycoma longifolia Jack (Tongkat Ali) on carbon tetrachloride-induced liver damage in rats. Malaysian Journal of Pharmaceutical Sciences. 2010; 8: 71-84. 
10. Chan KL, Low BS, Teh CH, Das PK. The effect of Eurycoma longifolia on sperm quality of male rats. Nat Prod Commun 2009;4:1331-6.

11. Low BS, Das PK, Chan KL. Standardized quassinoid-rich Eurycoma longifolia extract improved spermatogenesis and fertility in male rats via the hypothalamic-pituitary-gonadal axis. Journal of Ethnopharmacology 2013;145,706-714. 